\title{
A Review of 50 Cases of Aphakic Detachment in Peshawar, North West Frontier Province of Pakistan
}

\author{
*Zaman M, M.C.P.S., D.O.M.S., F.C.P.S. ${ }^{*}$ Hussain M, *Babar TF, ${ }^{* *}$ Wade PD, ${ }^{* *}$ Shah AA, M.C.P.S., F.C.P.S. \\ ${ }^{*}$ Khan M D
}

*Khyber Institute of Ophthalmic Medical Sciences, Hayatabad Medical Complex, Peshawar Pakistan **Dept of Ophthalmology, Jos University Teaching Hospital, Jos Nigeria ***Ayub Medical College, Abottabad, Pakistan

\begin{abstract}
\section{Background}

This prospective study was conducted at Khyber Teaching Hospital Peshawar, North West Frontier Province (NWFP) of Pakistan over the period of 16 months. It was to assess the demographic pattern, mode of presentation, treatment modalities and postoperative result of aphakic retinal detachment. This study also compared the incidence of aphakic retinal detachment in intracapsular versus extracapsular cataract extraction as well as the duration between cataract surgery and retinal detachment.
\end{abstract}

\section{Patients and Method}

A total of 50 patients were recruited in this prospective study. AProforma was specially designed for this purpose. Detailed history with reference to age, sex, presenting complaints, spectacle wear, previous ocular surgery, duration of surgery/ laser treatment, systemic and family history was taken. All patients had detailed ophthalmic examination, underwent conventional retinal reattachment surgery, and were followed up for 6 months.

\section{Results}

Of the total number studied, $86 \%$ of the patients were males; only $14 \%$ were females, with a mean age of 58 years.

The overall anatomical success was achieved in 40 (80\%) eyes. The visual acuity of $6 / 12$ and better was achieved in $8(16 \%)$ eyes. 20 (40\%) eyes attained a vision of $6 / 18$ to 6/36. 12 (24\%) eyes had a vision between $6 / 60$ to CF $3 m$. The vision could not be improved beyond CF $3 \mathrm{~m}$ in 10 (20\%) eyes.

\section{Conclusion}

Vitreous loss during cataract surgery is the most common cause of aphakic retinal detachment. The risk is maximal in the first and second year. The overall anatomical attachment achieved through conventional retinal detachment surgery is $80 \%$.

Key words: Retinal detachment, Vitreous loss, Intracapsular cataract extraction, Extracapsular cataract extraction surgery.
Date Accepted for publication: 11th June 2009

Nig J Med 2009; 263 - 268

Copyright @2009 Nigerian Journal of Medicine

\section{Introduction}

Retinal Detachment is defined as the separation of neurosensory retina from the retinal pigment epithelium by sub-retinal fluid.

Up to $40 \%$ cases of Retinal Detachment occurs in aphakic and pseudophakic eyes ${ }^{1 .}$ The incidence of retinal detachment is 2-5\% after Intracapsular cataract extraction (ICCE) and 1.4\% after extracapsular cataract extraction (ECCE). ${ }^{2}$

Surgical intervention is the only treatment for cataract but it carries certain complications. Vitreous loss, an important complication of cataract surgery, is a contributory factor leading to posterior segment complications like retinal detachment. ${ }^{3}$ The incidence of retinal detachment is more after ICCE because of the higher chance of vitreous loss / prolapse. ${ }^{4}$ Improvement in microsurgical techniques is responsible for the decline in retinal detachment following Cataract extraction. $^{5}$

ECCE is a safe procedure, but is associated with a very common complication of Posterior capsule opacification (PCO), resulting in postoperative reduction of visual acuity. ${ }^{6}$ The incidence of posterior capsule opacification is $25.4 \%$ to $29 \%$. ${ }^{7,8}$ \& For visual rehabilitation posterior capsulotomy (Nd: Yag Laser/ Surgery) is needed. The risk of retinal detachment increases if posterior capsule is opened at the time of surgery or as a secondary procedure.

Coonan et al reported an incidence of 3.2\% after primary $\mathrm{Nd}$ : Yag Capsulotomy. ${ }^{10}$ The prevalence of aphakic retinal detachment is very common in NWFP. It is a disease of all age groups but more common in the elderly population. If not diagnosed and treated on time can lead to blindness. Timely diagnosis and treatment 
can decrease the social and economic burden of the family concerned. The best available treatment is drainage of the subretinal fluid, cryotherapy, and scleral buckling.

(external tamponade). The complicated cases having proliferative vitreoretinopathy need the attention of Vitreoretinal surgeons and are best managed by them.

\section{Material and methods}

A total of 50 patients were recruited in this prospective study. All patients were admitted, detailed ophthalmic, medical, and family history was taken and recorded in a specially designed proforma. A note was made of the age, sex, presenting symptoms, duration of symptoms, previous ocular procedure (surgery/ laser treatment), duration of ocular procedure and previous/ present spectacle wear. The presenting symptoms were recorded as floaters, flashes of light, visual field defects and loss of vision.

All patients underwent a thorough ophthalmic assessment. Visual acuity both corrected and uncorrected was recorded. The presence of afferent pupillary defect was noted. Anterior and Posterior segments were examined thoroughly. A note was made of the corneal wound, presence of Vitreous in the anterior chamber, anterior uveitis, status of posterior capsule and intraocular pressure.

During dilated fundal examination, information regarding the location and extent of retinal detachment was recorded. The number, size, type and location of retinal breaks were noted. Presence and extent of sub-retinal fluid, mobility of the retina, status of the macula, presence of lattice and other degenerative changes were also recorded. All the details were converted to a retinal drawing. Fundus photographs were also taken.

The state of the fellow eye was recorded as phakic, aphakic, and pseudophakic. Presence of lattice, retinal degenerations, retinal breaks and detachment was also noted.

All the patients were operated under general anaesthesia. Standard retinal detachment techniques of break identification, sub-retinal fluid drainage, cryotherapy, scleral buckling, and local plombage were adopted.

First Post-operative dressing was done after 24 hours. Visual acuity, detailed anterior segment, posterior segment examination and Intraocular pressure measurement was carried out. The patients were discharged on $3^{\text {rd }}$ and $5^{\text {th }}$ postoperative day on topical steroids and antibiotics. All patients were followed up at two weeks, one month, two months, three months and thereafter at six months interval. All those patients having detached retina due to proliferative vitreoretinopathy were referred to vitreoretinal surgeons.

\section{Results}

Fifty cases of aphakic retinal detachment were analyzed. Forty three $(86 \%)$ patients were males while $7(14 \%)$ patients were females. The mean age was 58 years. Twenty six (52\%) patients were between 51 and 60 years of age, $10(20 \%)$ patients were between 61 and 70 years and $6(12 \%)$ patients between 41 and 50 years of age. The mode of presentation was recorded as floaters, flashes of light, visual field defects and visual loss. Fifteen $(30 \%)$ patients presented as floaters, visual field defect and loss of Vision.

Eleven (22\%) patients presented as visual field defects and loss of vision, while $10(20 \%)$ patients presented as loss of vision.

Forty five $(90 \%)$ patients had unilateral retinal detachment while only $5(10 \%)$ patients had bilateral retinal detachment.

All patients had undergone cataract surgery. Thirty $(60 \%)$ patients had extracapsular cataract extraction (ECCE) without intraocular lenses, Intracacpsular cataract extraction (ICCE) had been performed on 15 $(30 \%)$ patients. Five (10\%) patients were pseudophakic with posterior chamber intraocular lens implantation.

$18(36 \%)$ patients in the ECCE group had vitreous loss during cataract surgery, while only $2(4 \%)$ patients in the ICCE group had vitreous loss.

Retinal detachment occurred within 6 months to 2 years in $34(68 \%)$ patients. The maximum duration of retinal detachment after cataract extraction was above 5 years in only $3(6 \%)$ patients.

$3(6 \%)$ patients had Yag laser posterior capsulotomy. Two (4\%) patients had posterior capsulotomy between one to two years. Retinal detachment occurred within six months in all the three cases.

Twenty-one (42\%) eyes had all the four quadrants involved. Sixteen $(32 \%)$ eyes had three quadrants involved, in $2(4 \%)$ eyes one quadrant was involved. Twelve $(24 \%)$ eyes had only one break, while $7(14 \%)$ showed multiple breaks. No tear/hole was found in 31 (62\%) eyes. 
Macula was found detached in $33(66 \%)$ eyes at the time of presentation, while it was found attached in only $3(6 \%)$ eyes.

All the patients recruited in this study underwent surgery. Sub-retinal fluid was drained in $46(92 \%)$ cases while in 4 $(8 \%)$ cases it was left as such. The method used for chorioretinal adhesion was cryotherapy. It was used in 45 $(90 \%)$ eyes. Thirty six $(72 \%)$ eyes were encircled with a $2 \mathrm{~mm}$ wide silicone rubber band, $11(22 \%)$ eyes received localized buckling procedure with silicone plomb, while only $3(6 \%)$ eyes encircled in addition to local plombage.

The follow up was variable. Twenty (40\%) patients were followed up for 6 months, $15(30 \%)$ patients for 9 months and another $15(30 \%)$ patients for one year.

The commonest intra-operative complication was choroidal hemorrhage observed in $8(16 \%)$ patients. Inadvertent scleral perforation occurred in $4(8 \%)$ eyes which were repaired. Retinal Incarceration occurred in only $1(2 \%)$ eye. The most common post-operative complication was Proliferative Vitreoretinopathy in 8 $(16 \%)$ cases, macular pucker in $4(8 \%)$ eyes and choroidal detachment in $1(2 \%)$ eye.

The overall anatomical attachment was achieved in 40 $(80 \%)$ eyes. The Visual acuity of $6 / 12$ and better was achieved in $8(16 \%)$ patients.

The Results are shown in the following tables.

Table I: duration between cataract surgery and retinal detachment

\begin{tabular}{|lcc|}
\hline Duration of cataract surgery & Number of eyes & Percentage \\
0 6months & 12 & 24 \\
7 months -1 year & 10 & 20 \\
1 2 years & 12 & 24 \\
2 3 years & 9 & 18 \\
$3-4$ years & 2 & 4 \\
4 5 years & 2 & 4 \\
$>5$ years & 3 & 6 \\
Total & 50 & 100 \\
\hline
\end{tabular}

Table II: surgical complications

\begin{tabular}{|lcc|}
\hline Complications & Number of Eyes & Percentage \\
Proliferative vitreoretinopathy & 8 & 16 \\
Scleral Perforation & 4 & 8 \\
Macular Pucker & 4 & 8 \\
Choroidal Haemorrhage & 1 & 2 \\
Choroidal detachment & 1 & 2 \\
Muscle belly rupture & 1 & 2 \\
Hypotony & 1 & 2 \\
Retina incarceration & 1 & 2 \\
Into drainage site & & \\
\hline Total & 21 & 42 \\
\hline
\end{tabular}

Table III: visual outcome following surgical management

\begin{tabular}{|lcc|}
\hline Visual acuity & Number of patients & Percentage \\
$6 / 12$ and better & 8 & 16 \\
$6 / 18 \quad 6 / 36$ & 20 & 40 \\
$6 / 60$ counting & & \\
fingers at 3 meters & 12 & 24 \\
Less than counting & & \\
Fingers at 3 meters & 10 & 20 \\
Total & 50 & 100 \\
\hline
\end{tabular}

\section{Discussion}

Aphakic retinal detachment is one of the late complications of cataract surgery. It accounts for $40 \%$ of the retinal detachments. Previously a frequent cause of irreparable visual loss, aphakic retinal detachment is currently treated with increasing success by a variety of surgical techniques, including conventional retinal detachment surgery, vitrectomy with Silicone oil, gases and perflurocarbon.

Regarding aphakic retinal detachment there is no significant predilection for either sex. In our study $43(86 \%)$ patients were males while only $7(14 \%)$ were females. The mean age of the patients was 58 years; this is similar to that reported by Mohinder Singh in 1988. ${ }^{11}$ Most of the patients in our study presented with floaters $(30 \%)$, visual field defects $(22 \%)$ and poor vision (20\%). Hicichi and Trempe in $1994^{12}$ reported that in patients presenting with floaters and flashes of light, nearly $90 \%$ had posterior vitreous detachment and $11 \%$ had retinal breaks. In our study a very small number of patients (26\%) presented with one or two quadrant of the retina with breaks. In a study conducted by Jaffe $1984^{13}$, $44 \%$ of the eyes with retinal breaks had flashes of light, which suggests that light flashes are not related to retinal breaks.

The $10 \%$ incidence of bilaterality in our series is similar to a study $(6.1 \%)$ by Gray et al $\left.\right|^{5}$, but lower than that in a study by Ashrafzadeh et $\mathrm{al}^{14}$ who found the incidence of bilaterality to be $36.8 \%$ for aphakic eyes. This much higher figure may be due to the recruitment of large number of patients in the study.

In our study $70 \%$ of the eyes had undergone ECCE, out of which only $10 \%$ had posterior chamber IOL, while 30 $\%$ had ICCE. This is in contrast to a study conducted by Gray et al in $1989^{5}$ where $74 \%$ patients had ICCE and only $26 \%$ had ECCE. This was because most of the cataract surgeons had changed to extracapsular techniques in the late eighties.

Vitreous loss was found in $34 \%$ of ECCE and in $4 \%$ ICCE patients. These figures resemble those given by 


\section{Gray $^{5}$}

The risk of retinal detachment following cataract surgery is maximal in the first and second year, this being true for both ICCE and ECCE groups. Twenty patients $(24 \%)$ of aphakic retinal detachment occurred within 6 months, $20 \%$ within one year, $24 \%$ within 2 years and $18 \%$ within 3 years. This similarity has also been reported by $\mathrm{Smith}^{3}$ and Cousins. ${ }^{15}$

Six percent of the patients in our study had Yag laser capsulotomy 7 months to 2 years after cataract surgery. Retinal detachment occurred in all these cases within 6 months. In most of the studies, ${ }^{3,7816}$ the incidence of retinal detachment following Yag Laser Capsulotomy ranges from $1 \%$ to $3.6 \%$.

In our study, $74 \%$ of the patients had involvement of three or all four quadrants of the fundus, $22 \%$ had two quadrants involved and only one quadrant was involved in $4 \%$ cases. These figures are broadly similar to a study conducted by Mohinder Singh in $1988 .{ }^{11}$ In his study; three or all four quadrants were involved in $75 \%$ of the cases. In $24 \%$ patients of our study, a single retinal break was found, while $14 \%$ of the patients had multiple retinal tears/holes. In $62 \%$ cases no retinal break was localized. This was due to total bullous retinal detachment of the retina or probably due to anterior location of very small tears or holes. Moreover in most of the cases we were unable to see details in the periphery of the fundus, because of total R/D in large number of cases, postoperative posterior synechiae, capsular opacification and poor dilatation of the pupil. In other studies a single retinal break was localized in $71 \%$ of aphakic R/D and multiple breaks were seen in $29 \%$ of cases. ${ }^{17}$

In our study $66 \%$ of the patients had a detached macula, while only $6 \%$ had an attached macula. The involvement of macula was probably due to rapid progression to total separation in aphakic R/D.

Seventy two percent patients were treated with encirclement, $22 \%$ with local buckling procedures and $6 \%$ with local buckling and encirclement. The success rate of reattachment with encirclement $(86.10 \%)$ was better as compared to local buckling procedure $(54.54 \%)$, while the combination of the two procedures had a success rate of

\section{References}

1. Lucy HY. Young and Donald JD. Retinal Detachment: Principles and Practice of Ophthalmology: Vol. 2 WB Saunders Company, 1994; 1084-92.

2. Smith PW, Stark WJ, Maunmenee AE et al. Retinal Detachment after Extracapsular Cataract Extraction with posterior chamber intraocular lens. Ophthalmology 1987; 94 : 495.
$100 \%$. Sub-retinal fluid was drained in $92 \%$ cases, because majority of the patients had total or sub-total retinal detachment.

Cryotherapy was used in $90 \%$ of the patients to create sterile inflammation for successful chorioretinal adhesion.

The operative complication in $16 \%$ of patients was Choroidal hemorrhage. In other study it was found to be $7.5 \% .^{11}$ The higher rate of Choroidal hemorrhage was mainly due to excessive application of cryotherapy and drainage of sub-retinal fluid. The other complications were Scleral perforation (8\%), Retinal incarceration into drainage site $(2 \%)$, hypotony $(2 \%)$, and rupture of the muscle belly $(2 \%)$.

The important postoperative complications were Proliferative vitreoretinopathy (PVR) in 16\%, macular pucker in $8 \%$ and Choroidal detachment in $2 \%$ cases. The increase rate of these complications is due to pigment release by excessive application of Cryotherapy.

The overall anatomical success was achieved in $80 \%$ of the patients which is slightly low as compared to $85 \%$ in another study ${ }^{18}$. We also observed favourable functional results. Visual Acuity of $6 / 12$ or better in $16 \%$ of patients, $6 / 18-6 / 36$ in $40 \%$ and $6 / 60$ to CF $3 \mathrm{~m}$ in $25 \%$ patients. This is comparable to the results by William et al. ${ }^{17}$ The better results were because the subsequent macula involving retinal detachment cases were avoided. The less favourable results were because of the long standing retinal detachment and macular involvement. In a study conducted by Mohinder Singh, ${ }^{11}$ the final Visual acuity was $6 / 6-6 / 12$ in $28.85 \%, 6 / 18$ $6 / 36$ in $37.90 \%$ and $6 / 60$ to CF in $33.25 \%$ eyes. Results were compared to our study and it was found that the difference is not significant statistically.

\section{Conclusion}

Males are more frequently involved than females in our setup. Vitreous loss during cataract surgery is the most important cause of aphakic retinal detachment. Yag laser capsulotomy can cause retinal detachment. Conventional retinal detachment surgery is effective in most of the patients.

3. Hugh MC, Wong D, Chignall A et al. Arch-Clin Exp-Ophth, 1991; 229:521-5.

4. John SFS. The Surgical Management of Cataract: Community Eye Health. Issue No 08 1991:9.

5. Gray RH, Evan AR, Constable IJ, Mc Alistair IL. Retinal Detachment and its relation to Cataract Surgery. BJ Ophthalmol 1989; 73: 775-80.

6. Frao DS, Lam DS, Li KK Ophthalmology 1999 April; 106(4):688-91. 
7. Jamal A. Risk of Retinal Complication after $\mathrm{Nd}$ : YAG Capsulotomy in axial Myopia. Pak J Ophthalmol. 1989; 117-8.

8. Khwaja Sharif ul Hassan, M Idrees, Misbahul Aziz, Musrat shah, Mansoor Farouqi. Nd YAG Laser Posterior Capsulotomy. Pak J Ophthalmol. 1996; 12: 3-7.

9. Caroline J, McEwen and Gordon N, Dutto N. Nd|: Yag Laser in the management of Posterior Capsule Opacification. Complications and current trends. Trans Ophthalmol. SOC UK 1986; 105: 337-43.

10. Coonan P, Fung WE, Webster LG, Allen AW, Abbott RL. Incidence of Retinal Detachment following Extracapsular Cataract Extraction. Ophthalmology 1985; 92: 1091-101.

11. Singh M. Surgery of Aphakic Retinal Detachment. BJ Ophthalmol, 1988: 72; 820-22.

12. Hikichi T, Trempe CL. Relationship between Floaters, light flashes or both and complications of Posterior Vitreous Detachment, Am J Ophthalmol, May 1994: 117; 593-8.

13. Jaffe NS, Clayman HM, and Jaffe MS. Retinal Detachment in myopic eyes after intracapsular and extracapsular cataract extraction. Am J Ophthalmol 1984: 97; 48.
14. Ashraf Zadeh MT, Schepens CL, Elzeneiny IH, Moura R, Morse P, Kraushar MF. Aphakic and Phakic Retinal Detachment. Arch Ophthalmol 1973: 89; 476.

15. Cousins.S.Boniuk L, Okun E, et al. Pseudophakic Retinal Detachment in the presence of various IOL types. Ophthalmology, 1986:93; 1198-208.

16. Chang Gung, Ku We, Chuang LH, Lai. Cataract extraction in high Myopic eyes. Med J 2002; 25: 315-20.

17. William E, Smiddy MD, Harry W, Flynn Jr, Don H Nicholson MD. Results and complications in treated Retinal breaks. Am J Ophthalmol Dec 1991; 112: 623-31.

18. Katedry Okulisty, Kizkinika Okulisty, Narzadu Wzroku PAM. Results of Retinal Detachment surgery in Aphakic and Pseudophakic eyes. Klin Oczna 1999;101: 99-101.

19. Combs JL and Welch RB. Retinal breaks without Detachment. Natural History, management and long term follow up. Trans Am J Ophthalmol 1982; 80-64. 